\section{E7 Ülkelerinde Satınalma Gücü Paritesinin Geçerliliğinin Doğrusal ve Doğrusal Olmayan Birim Kök Testleri ile Analizi}

\author{
Burak GÜRIŞ̧*, Yaşar Serhat YAŞGÜL ${ }^{* *}$, Muhammed TIRAȘOĞLU**
}

Öz

Uluslararası ekonominin ilgi çeken konularından olan Satınalma Gücü Paritesi, farklı ülke ve ülke grupları için birçok araştırmacı tarafından analiz edilmiştir. Bu çalışmanın amacı, gelişen yedi ülkede (E7) Satınalma Gücü Paritesi'nin geçerliliğinin uygun ekonometrik yöntemler ile analiz edilmesidir. Bu amaçla öncelikle reel döviz kuru serilerinin doğrusal olup olmadığı Harvey ve Leybourne (2007) ve Harvey vd. (2008) doğrusallık testleri ile incelenmiştir. Doğrusal seriler için Satınalma Gücü Paritesi geçerliliği Lee ve Strazicich (2003) iki yapısal kırılmaya izin veren birim kök testi ile analiz edilmiştir. Doğrusal olmayan seriler için Satınalma Gücü Paritesi geçerliliği Sollis (2009) doğrusal olmayan birim kök testi ile analiz edilmiştir. Analiz sonucunda, doğrusal seriler için sadece Brezilya ve Hindistan'da sabitte ve trendde kırılmaya izin veren modelde Satınalma Gücü Paritesi geçerlidir. Doğrusal olmayan seriler için ise sadece Çin'de ortalamadan arındırılmış modelde Satınalma Gücü Paritesi geçerlidir. Elde edilen bulgular birçok durumda E7 ülkelerinde Satınalma Gücü Paritesinin geçerliliğinin kabul edilmediğini göstermektedir.

Anahtar Kelimeler: Satınalma Gücü Paritesi, E7 Ülkeleri, Doğrusallık Testi, Birim Kök Testi, Doğrusal Olmayan Birim Kök Testleri.

\section{Özgün Araştırma Makalesi (Original Research Article)}

Geliș Tarihi: 20.07.2017 Kabul Tarihi: 07.12.2017

DOI: http://dx.doi.org/10.17336/igusbd.387999

${ }^{*}$ Doç. Dr., İstanbul Üniversitesi, İktisat Fakültesi, Ekonometri Bölümü Öğretim Üyesi, İstanbul, Türkiye, E-posta: bguris@istanbul.edu.tr ORCID ID https://orcid.org/0000$\underline{0003-0562-4130}$

${ }^{* *}$ Yrd. Doç. Dr., Marmara Üniversitesi, İktisat Fakültesi, İktisat Bölümü Öğretim Üyesi, İstanbul, Türkiye, E-posta: yserhat@marmara.edu.tr ORCID ID https://orcid.org/0000-0001-6039-2155

${ }^{* * *}$ Yrd. Doç. Dr., Kırklareli Üniversitesi, İ.İ.B.F., Ekonometri Bölümü Öğretim Elemanı, Kırklareli, Türkiye, E-posta: muhammedtirasoglu@klu.edu.tr ORCID ID https://orcid.org/0000-0003-4345-1859
Sayfa/Page | 33

IGU J. Soc. Sci., 4 (2), Spec. Iss. of ICEFM 2017, pp. 33-46. 


\section{Analysis of the Validity of Purchasing Power Parity in E7 Countries Through Linear and Non-Linear Unit Root Tests}

Sayfa/Page | 34

İGÜ Sos. Bil. Derg., 4 (2), ICEFM 2017, Özel Sayısı, ss. 33-46.

\section{Abstract}

Purchasing Power Parity has been one of the most popular topics in international economy and has been studied by many researchers for different countries and country groups to date. The purpose of this study is to analyze the validity of the Purchasing Power Parity in emerging seven countries (E7) using relevant econometric methods. The Harvey and Leybourne (2007) and Harvey et al. (2008) linearity tests have been used to investigate the linearity of real exchange rate series. The validity of the Purchasing Power Parity was analyzed using the Lee and Strazicich (2003) unit root test that allows for two structural breaks for linear series. The Purchasing Power Parity for nonlinear series was analyzed using the Sollis (2009) nonlinear unit root test. As a result of the analysis, purchasing power parity is valid only for the model that allows for breaks in both the level and trend in Brazil and India for linear series. Purchasing power parity is valid only in the demeaned model for China. The findings indicate that the validity of the Purchasing Power Parity is not accepted for E7 countries in many cases.

Keywords: Purchasing Power Parity, E7 Countries, Linearity Test, Unit Root Test, Non-Linear Unit Root Tests.

\section{Giriş}

Uluslararası ekonominin önemli ve tartışmalı konuları arasında yer alan Satınalma Gücü Paritesi (PPP), birçok araştırmacının ilgisini çekmiştir. İlk defa İsveçli iktisatçı Gustav Cassel (1918) tarafından literatüre kazandırılan PPP, 1973 yılında Bretton Woods sisteminin çökmesi ile daha fazla araştırma alanı bulmuştur.

Genel olarak PPP, ülkeler arasındaki fiyat düzeyi farklılıklarını ortadan kaldırarak, farklı para birimlerinin satınalma gücünü eşitleyen bir değişim oranı şeklinde tanımlanabilmektedir. PPP belirli bir mal ve hizmet sepetinin satın alınabilmesi için gereken ulusal para tutarlarının oranı şeklinde hesaplanmaktadır. ${ }^{1}$ Başka bir ifade ile iki ülke arasındaki döviz kuru, ekonomilerdeki sabit bir mal ve hizmet sepeti için bu iki ülkenin fiyat seviyesinin oranına eşit olmalıdır. Bir ülkenin yerel fiyat seviyesi arttıkça, PPP’ye geri dönmek için o ülkenin döviz kuru değeri düşürülmelidir. Aslında, bir ülkenin enflasyon oranı başka bir ülkenin enflasyon oranına göre yükseldiğinde, ihracatın azalması ve ithalatın artması ülkenin para birimini

${ }^{1}$ TÜİK, Satınalma Gücü Paritesi. TÜİK Yayınları, Yayın No:3145, Ankara, 2008, s.1. 
aşağıya çekmektedir. Burada PPP teorisi rol oynamaktadır ve enflasyon-döviz kuru ilişkisini ölçmeye çalışmaktadır.2

PPP ile ilgili ilk literatür çalışmalarının odak noktası gelişmiş ülkelerde Bretton Woods sonrası dönemin kısa verileri için zaman serisi analizine dayanmaktadır. Literatürün çoğunda PPP lehine bir delil bulunamadığı, dolayısıyla PPP'nin geçerli olmadığı sonucuna varılmıştır. Bazı ekonomistler, PPP lehine kanıt bulamamasının nedeni olarak kullanılan kısa örneklem büyüklügünü ve/veya standart testlerdeki güç eksikliğine bağlı olduğunu savunmaktadır. ${ }^{3}$ Günümüzde PPP’nin geçerliliğinin araştırılmasında örneklem büyüklügünün artması ve geliştirilen yeni ve güçlü ekonometrik yöntemler ile daha güvenilir sonuçların elde edilmesi mümkün hale gelmiştir.

PPP yaygın olarak mutlak ve nispi PPP olarak iki șekilde ele alınabilmektedir. Mutlak PPP'nin geçerli olması, iki farklı ülkede bir ürün grubunun belirlenen kurda fiyatlarının eşitlenmesi anlamına gelirken, nispi PPP'nin geçerli olması bir periyotta iki para birimi arasındaki döviz kurunda meydana gelen yüzde değişmelerin ülkelerin kendi fiyat düzeylerindeki yüzde değişmeler arasındaki farka eşit olduğunu göstermektedir ${ }^{4}$

Satınalma Gücü Paritesinin geçerliliğinin araştırılmasında literatürde farklı yöntemler bulunmakla birlikte, yaygın olarak kullanılan reel döviz kurunun durağanlığının araştırılmasıdır. Farklı özelliklere sahip durağanlık testleri kullanılarak ülke veya ülke grupları için PPP'nin geçerliliği birçok araştırmacı tarafından incelenmiştir.

$\mathrm{Bu}$ çalışmanın amacı gelişen yedi (E7) ülkelerinde Satınalma Gücü Paritesinin geçerliliğinin uygun ekonometrik yöntemler ile analiz edilmesidir. $\mathrm{Bu}$ amaçla çalışmanın devamında E7 'yi oluşturan ülkelerde Satınalma Gücü Paritesinin geçerliliğini araştıran çalışmalara yer verilecektir. 3. bölümde uygulamada kullanılacak ekonometrik yöntemler tanıtılacaktır. Çalışmanın 4. bölümünde E7 ülkeleri için PPP geçerliliği uygulama sonuçları yer alacak ve sonuç bölümü ile çalışma tamamlanacaktır.

\footnotetext{
2 Kalsoom Akhtar, et al. "Purchasing Power Parity: Implacation with Respect to Pakistan and USA", Research Journal of Finance and Accounting, Vol.5(4), 2014, s.193.

${ }^{3}$ Salah A. Nusair, "Testing the Validty of Puchasing Power Parity for Asian countries During the Current Float", Journal of Economic Development, Vol.28(2), 2003, s.130.

${ }^{4}$ Sefer Şener, Veli Yılancı, Esra Canpolat, "Satın Alma Gücü Paritesi ve Varyasyonlarının Türkiye için Sınanması", Uluslararası Yönetim Íktisat ve Issletme Dergisi, Vol.11(5), 2015, p. 54.
}

Sayfa/Page | 35

IGU J. Soc. Sci., 4 (2), Spec. Iss. of ICEFM 2017, pp. 33-46. 
Sayfa/Page | 36

İGÜ Sos. Bil. Derg., 4 (2), ICEFM 2017 Özel Sayısı, ss. 33-46.

\section{Literatür}

PPP’nin geçerliliğini farklı ekonometrik yöntemler ile araştırıldığı birçok çalışma mevcuttur. Yapılan çalışmalarda, PPP geçerliliğine ilişkin ortak bir sonuca ulaşılamadığı görülmektedir. Bunun nedenleri arasında, ele alınan ülke veya ülke grubunun, inceleme döneminin ve kullanılan ekonometrik yöntemlerin farklılıkları gösterilebilmektedir. Tablo 1'de PPP'nin geçerliliğini araştıran literatürdeki çalışmalar yer almaktadır.

Tablo 1: PPP ile İlgili Literatür Özeti

\begin{tabular}{|c|c|c|c|c|}
\hline Yazar & Ülke & Veri Dönemi & Yöntem & Bulgu \\
\hline $\begin{array}{l}\text { Cerrato ve } \\
\text { Sarantis (2007) }\end{array}$ & $\begin{array}{l}34 \text { Gelişmekte } \\
\text { Olan Ülke }\end{array}$ & $\begin{array}{l}\text { Ocak 1973- } \\
\text { Aralık } 1998\end{array}$ & $\begin{array}{l}\text { Panel Eşbütünleşme } \\
\text { Testi }\end{array}$ & PPP geçerli \\
\hline $\begin{array}{l}\text { Hooi ve Smyth } \\
\text { (2007) }\end{array}$ & 15 Asya Ülkesi & $\begin{array}{l}\text { Ocak 1995- } \\
\text { Ekim } 2004\end{array}$ & $\begin{array}{l}\text { Kırılmalı Panel Birim } \\
\text { Kök Testi }\end{array}$ & PPP geçerli \\
\hline $\begin{array}{l}\text { Bahmani- } \\
\text { Oskooee, Hegerty } \\
\text { ve Kutan (2009) }\end{array}$ & 52 Ülke & $\begin{array}{l}\text { Ocak 1994- } \\
\text { Aralık } 2006\end{array}$ & Birim kök testi & $\begin{array}{l}\text { Çin ve Hindistan'da } \\
\text { PPP geçerli }\end{array}$ \\
\hline $\begin{array}{l}\text { Çağlayan ve Şak } \\
\text { (2009) }\end{array}$ & OECD Ülkeleri & $\begin{array}{l}\text { Ocak 1996- } \\
\text { Nisan } 2006\end{array}$ & $\begin{array}{l}\text { Panel Eşbütünleşme } \\
\text { Testi }\end{array}$ & PPP geçerli değil \\
\hline $\begin{array}{l}\text { Bozoklu ve } \\
\text { Yılancı (2010) }\end{array}$ & E7 Ülkeleri & $\begin{array}{l}\text { Ocak 1995- } \\
\text { Aralık } 2009\end{array}$ & $\begin{array}{l}\text { Kırılmalı Birim Kök } \\
\text { Testi }\end{array}$ & $\begin{array}{l}\text { Çin ve Meksika'da PPP } \\
\text { geçerli }\end{array}$ \\
\hline $\begin{array}{l}\text { Chang, Su, Zhu } \\
\text { ve Liu (2010) }\end{array}$ & BRIC Ülkeleri & $\begin{array}{l}\text { Temmuz 1992- } \\
\text { Aralık } 2006\end{array}$ & $\begin{array}{l}\text { Doğrusal Olmayan } \\
\text { Eşbütünleşme Testi }\end{array}$ & $\begin{array}{l}\text { Çin'de PPP geçerli } \\
\text { değil, Diğer ülkelerde } \\
\text { PPP geçerli }\end{array}$ \\
\hline $\begin{array}{l}\text { Chang, Lee ve } \\
\text { Hung (2012) }\end{array}$ & BRICS Ülkeleri & $\begin{array}{l}\text { Ocak 1996- } \\
\text { Temmuz } 2010\end{array}$ & $\begin{array}{l}\text { Doğrusal Olmayan } \\
\text { Eşbütünleşme Testi }\end{array}$ & $\begin{array}{l}\text { Brezilya haric diğer } \\
\text { ülkelerde PPP geçerli }\end{array}$ \\
\hline $\begin{array}{l}\text { Bahmani- } \\
\text { Oskooee, Chang } \\
\text { ve Lee (2014) }\end{array}$ & $\begin{array}{l}\text { BRICS ve MIST } \\
\text { Ülkeleri }\end{array}$ & $\begin{array}{l}\text { Ocak 1994- } \\
\text { Haziran } 2012\end{array}$ & $\begin{array}{l}\text { Doğrusal, Doğrusal } \\
\text { Olmayan ve Panel } \\
\text { Birim Kök Testleri }\end{array}$ & $\begin{array}{l}\text { Her durum için karışık } \\
\text { sonuçlar bulunmuştur }\end{array}$ \\
\hline Tiraşoğlu (2014) & OECD Ülkeleri & $\begin{array}{l}\text { Q1 1993- Q1 } \\
2011\end{array}$ & $\begin{array}{l}\text { Kırılmalı Birim Kök } \\
\text { Testleri }\end{array}$ & $\begin{array}{l}\text { Kanada ve Meksika'da } \\
\text { PPP geçerli }\end{array}$ \\
\hline $\begin{array}{l}\text { Çeviş ve Ceylan } \\
\text { (2015) }\end{array}$ & Kırılgan 5 Ülkeleri & $\begin{array}{l}\text { Ocak 2003- } \\
\text { Ağustos } 2013\end{array}$ & $\begin{array}{l}\text { Johansen } \\
\text { Eşbütünleşme Testi }\end{array}$ & $\begin{array}{l}\text { Endonezya'da PPP } \\
\text { geçerli değil }\end{array}$ \\
\hline $\begin{array}{l}\text { Peng, Liu ve } \\
\text { Chang (2016) }\end{array}$ & BRICS Ülkeleri & $\begin{array}{l}\text { Ocak 1995- } \\
\text { Şubat } 2015\end{array}$ & Kantil Birim Kök Testi & $\begin{array}{l}\text { Tüm Ülkelerde PPP } \\
\text { geçerli }\end{array}$ \\
\hline $\begin{array}{l}\text { Güriş, Yaşgül ve } \\
\text { Tıraşoğlu (2016) }\end{array}$ & NORDIC Ülkeleri & $\begin{array}{l}\text { Ocak 2009- } \\
\text { Aralık } 2014\end{array}$ & $\begin{array}{l}\text { Doğrusal ve Doğrusal } \\
\text { Olmayan Birim Kök } \\
\text { Testleri }\end{array}$ & $\begin{array}{l}\text { NORDIC Ülkelerinde } \\
\text { PPP geçerli değil }\end{array}$ \\
\hline $\begin{array}{l}\text { Bahmani- } \\
\text { Oskooee vd. }\end{array}$ & 7 Geçiş Ülkesi & $\begin{array}{l}\text { Ocak 1998- } \\
\text { Mart } 2015\end{array}$ & Kantil Birim Kök Testi & PPP geçerli \\
\hline $\begin{array}{l}\text { Güriş ve } \\
\text { Tıraşoğlu (2017) }\end{array}$ & BRICS Ülkeleri & $\begin{array}{l}\text { Ocak 1993-Mart } \\
2015\end{array}$ & $\begin{array}{l}\text { Doğrusal Olmayan } \\
\text { Birim Kök Testi }\end{array}$ & $\begin{array}{l}\text { Brezilya ve Güney } \\
\text { Afrika'da PPP geçerli }\end{array}$ \\
\hline
\end{tabular}




\section{Metodoloji}

PPP'nin geçerliliğinin araştırılmasında yaygın olarak tercih edilen yöntem birim kök testleridir. Reel döviz kuru serisinin yapısına uygun birim kök testlerinin kullanılması elde edilecek sonuçların güvenilirliği açısından önemlidir. Eğer reel döviz kuru durağan ise, şoklar geçici etki gösterecek, bu durum PPP’nin geçerli olduğunu göstermektedir. Reel döviz kuru birim kök içeriyor ise şoklar kalıcı etki gösterecek, bu durum satın alma gücü paritesinin geçerli olmadığı anlamına gelmektedir. ${ }^{5}$

Reel döviz kuru serilerini durağan olup olmadığını araştırmadan önce serilerin doğrusal olup olmadığının araştırılması önemlidir. Literatürde birçok doğrusallık testinin geliştirildiği görülmektedir. Bu testler arasında durağanlık seviyelerinden etkilenmediği temel avantajı göz önünde bulundurularak, Harvey ve Leybourne (2007)6 ve Harvey vd. (2008)7 tarafından geliştirilen testler üzerinde durulacaktır. ${ }^{8}$

Harvey ve Leybourne (2007) çalışmasında I(0) ve I(1) süreçlerin varlığına birlikte izin veren aşağıdaki denklemin kullanılmasını önermiştir.

$\mathrm{y}_{\mathrm{t}}=\beta_{0}+\beta_{1} \mathrm{y}_{\mathrm{t}-1}+\beta_{2} \mathrm{y}_{\mathrm{t}-1}^{2}+\beta_{3} \mathrm{y}_{\mathrm{t}-1}^{3}+\beta_{4} \Delta \mathrm{y}_{\mathrm{t}-1}+\beta_{5}\left(\Delta \mathrm{y}_{\mathrm{t}-1}\right)^{2}+\beta_{6}\left(\Delta \mathrm{y}_{\mathrm{t}-1}\right)^{3}+\varepsilon_{\mathrm{t}}$

İlgili denklemde doğrusallık testi için temel ve alternatif hipotez aşağıdaki gibi olacaktır.

$$
\begin{aligned}
& \mathrm{H}_{0}: \beta_{2}=\beta_{3}=\beta_{5}=\beta_{6}=0 \\
& \mathrm{H}_{1}: \beta_{2} \neq \beta_{3} \neq \beta_{5} \neq \beta_{6} \neq 0
\end{aligned}
$$

Harvey ve Leybourne (2007) çalışmasında test istatistiği,

$$
\begin{array}{r}
\mathrm{W}_{\mathrm{T}}=\frac{\mathrm{RSS}_{1}-\mathrm{RSS}_{0}}{\mathrm{RSS}_{0} / \mathrm{T}} \\
\mathrm{W}_{\mathrm{T}}^{*}=\exp \left(-\mathrm{b}\left|\mathrm{DF}_{\mathrm{T}}\right|^{-1}\right) \mathrm{W}_{\mathrm{T}}
\end{array}
$$

şeklindedir. Eşitlikte b sıfır olmayan sabit, $\mathrm{DF}_{\mathrm{T}}$ kısıtlı regresyondan elde edilen standart ADF $t$ istatistiğidir. $\mathrm{RSS}_{\mathrm{i}} \mathrm{H}_{\mathrm{i}}$ hipotezi için hata terimi kareler

5 Juan Carlos Cuestas and Jose Regis "Purchasing Power Parity in OECD Countries: Nonlinear Unit Root Tests Revisited" Economic Modelling, Vol.32, 2013.

${ }^{6}$ David I. Harvey and Stephen J. Leybourne, "Testing for Time Series Linearity", Econometrics Journal, Vol.10, 2007, s.149-165.

${ }^{7}$ David I. Harvey, and Stephen J. Leybourne and Bin Xiao, "A Powerful Test for Linearity When the Order of Integration is Unknown". Studies in Nonlinear Dynamics \& Econometrics, Vol.12 (3), 2008, (article 2).

${ }^{8}$ Burak Güriş, Yaşar Serhat Yaşgül and Muhammed Tıraşoğlu, "An Empirical Investigation of Purchasing Power Parity (PPP) for NORDIC Countries: Evidence from Linear and Nonlinear Unit Root Tests", International Journal of Economic Perspectives, Vol. 10(1), 2016, s. 133.

Sayfa/Page | 37

IGU J. Soc. Sci., 4 (2), Spec. Iss. of ICEFM 2017, pp. 33-46. 
Sayfa/Page | 38

İGÜ Sos. Bil. Derg., 4 (2), ICEFM 2017, Özel Sayısı, ss. 33-46. toplamını, T ise gözlem sayısını ifade etmektedir. Harvey ve Leybourne (2007) test istatistiği $\chi_{4}^{2}$ dağılımına uygunluk gösterir.

Harvey vd. (2008) testinin uygulanması için, zaman serisinin durağan (I(0)) ve durağan olmama (I(1)) varsayımı altında kullanılacak modeller sırasıyla aşağıdaki gibidir.

$$
\begin{aligned}
\mathrm{y}_{\mathrm{t}} & =\beta_{0}+\beta_{1} \mathrm{y}_{\mathrm{t}-1}+\beta_{2} \mathrm{y}_{\mathrm{t}-2}^{2}+\beta_{3} \mathrm{y}_{\mathrm{t}-3}^{3}+\sum_{\mathrm{j}=1}^{\mathrm{p}} \beta_{4, \mathrm{j}} \Delta \mathrm{y}_{\mathrm{t}-\mathrm{j}}+\varepsilon_{\mathrm{t}} \\
\Delta \mathrm{y}_{\mathrm{t}} & =\lambda_{1} \Delta \mathrm{y}_{\mathrm{t}-1}+\lambda_{2}\left(\Delta \mathrm{y}_{\mathrm{t}-1}\right)^{2}+\lambda_{3}\left(\Delta \mathrm{y}_{\mathrm{t}-1}\right)^{3}+\sum_{\mathrm{j}=1}^{\mathrm{p}} \lambda_{4, \mathrm{j}} \Delta \mathrm{y}_{\mathrm{t}-\mathrm{j}}+\varepsilon_{\mathrm{t}}
\end{aligned}
$$

Eşitlikte $\Delta$ fark operatörü ve p gecikme sayısını göstermektedir. Durağan durum için hesaplanan $W_{0}$ ve durağan olmayan durum için hesaplanan $\mathrm{W}_{1}$ test istatistikleri ile Harvey vd. (2008) $\mathrm{W}_{\lambda}$ test istatistiğ hesaplanmaktadır. $W_{\lambda}$ test istatistiği $\chi_{2}^{2}$ dağılımına uygunluk göstermektedir.

$\mathrm{W}_{\lambda}=\{1-\lambda\} \mathrm{W}_{0}+\lambda \mathrm{W}_{1}$

İlgili serilerin doğrusal olup olmadıkları belirlendikten sonra uygun birim kök testi ile PPP'nin geçerliliği araştırılabilecektir. Doğrusal yapıya sahip seriler için Lee ve Strazicich (2003) ${ }^{9}$ iki yapısal kırılmaya izin veren birim kök testi kullanılacaktır. Lee ve Strazicich tarafından önerilen Lagrange Çarpanı (LM) birim kök testi için regresyon aşağıdaki gibidir.

$$
y_{t}=\delta^{\prime} Z_{t}+e_{t} \quad e_{t}=\beta e_{t-1}+\varepsilon_{t}
$$

Burada $Z_{t}$ dişsal değişkenler vektörü göstermekte ve $\varepsilon_{t} \sim$ iid $N\left(0, \sigma^{2}\right)$ 'dir. İki kırılmalı LM birim kök test istatistiği,

$$
\Delta y_{t}=\delta^{\prime} \Delta Z_{t}+\phi \tilde{S}_{t-1}+u_{t}
$$

şeklindedir. Birim kök temel hipotezinin sınanması için kullanılan test istatistiği $\phi$ parametresinin $\mathrm{t}$ test istatistiğidir ve $\tilde{\tau}$ ile ifade edilmektedir. Kırılma tarihleri, verinin \%15 baştan ve sondan kırpılması sonrasında kalan tarihler arasından $\tilde{\tau}$ test istatistiğinin minimum olduğu noktalardan $\operatorname{Inf} \tilde{\tau}(\tilde{\lambda})=\inf _{\lambda} \tilde{\tau}(\lambda) \quad$ seçilmektedir. Uygun model için kritik değerler ilgili çalışmada tablolaştırılmıştır.

9 Junsoo Lee and Mark C. Strazicich, "Minimum Lagrange Multiplier Unit Root Test with Two Structural Breaks", The Review of Economics and Statistics, Vol.85(4), 2003, s.1082-1089. 
Doğrusal olmayan yapıya sahip seriler için Sollis (2009) ${ }^{10}$ birim kök testi kullanılacaktır. Kapetanios vd. (2003) ${ }^{11}$ doğrusal olmayan birim kök testinde ortalamaya dönüşün simetrik olduğu varsayılmaktadır. Bu varsayım negatif ve pozitif sapmaların aynı etkiye sahip olduğu anlamına gelmektedir. Sollis (2009) yaptığı çalışma ile bu varsayımı genişletmiş ve simetrik veya asimetrik doğrusal olmayan ayarlamalara izin veren test prosedürü geliştirmiştir. Sollis (2009) tarafından geliştirilen test, hem üstel fonksiyonu hem de lojistik fonksiyonu kullanmaktadır. Geçiş değişkeninin $y_{t-1}$ olduğu varsayarak model aşağıdaki gibi ifade edilebilmektedir.

$$
\begin{array}{ll}
\Delta y_{t}=G_{t}\left(\gamma_{1}, y_{t-1}\right)\left\{S_{t}\left(\gamma_{2}, y_{t-1}\right) \rho_{1}+\left(1-S_{t}\left(\gamma_{2}, y_{t-1}\right)\right) \rho_{2}\right\} y_{t-1}+\varepsilon_{t} \\
G_{t}\left(\gamma_{1}, y_{t-1}\right)=1-\exp \left(-\gamma_{1}\left(y_{t-1}^{2}\right)\right) & \gamma_{1} \geq 0 \\
S_{t}\left(\gamma_{2}, y_{t-1}\right)=\left[1+\exp \left(-\gamma_{2} y_{t-1}\right)\right]^{-1} & \gamma_{2} \geq 0
\end{array}
$$

Burada $\varepsilon_{t}=i i d\left(0, \sigma^{2}\right)$ şeklindedir. Teste ait AESTAR modeli ilk denklem yardımıyla yüksek dereceden dinamiklere izin vermek için aşağıdaki gibi genişletilebilmektedir.

$$
\Delta y_{t}=G_{t}\left(\gamma_{1}, y_{t-1}\right)\left\{S_{t}\left(\gamma_{2}, y_{t-1}\right) \rho_{1}+\left(1-S_{t}\left(\gamma_{2}, y_{t-1}\right)\right) \rho_{2}\right\} y_{t-1}+\sum_{i=1}^{k} \kappa_{i} \Delta y_{t-i}+\varepsilon_{t}
$$

Sollis (2009) testinde Taylor çözümü gerçekleştirilerek denklemin genişletilmiş versiyonu,

$$
\Delta y_{t}=\phi_{1} y_{t-1}^{3}+\phi_{2} y_{t-1}^{4}+\sum_{i=1}^{k} \kappa_{i} \Delta y_{t-i}+\eta_{t}
$$

şeklindedir. Sollis (2009) testi için F test istatistiği aşağıdaki gibidir.

$$
F=(R \hat{\beta}-r)^{\prime}\left[\hat{\sigma}^{2} R\left\{\sum_{t} x_{t} x_{t}^{\prime}\right\}^{-1}\right](R \hat{\beta}-r) / m
$$

Sollis (2009) çalışmasında F testinin kritik değerlerini üç durum için tablolaştırmıştır.

\footnotetext{
${ }^{10}$ R. Sollis, "A Simple Unit Root Test against Asymmetrical STAR Nonlinearity with an Application to Real Exchange Rates in Nordic Countries". Economic Modelling, Vol.26(1), 2009, s. 118-125.

11 George Kapetanios, Yongcheol Shin, and Andy Snell, "Testing for a Unit Root in the Nonlinear STAR Framework", Journal of Econometrics, Vol.112, 2003, s. 359-379.
}

Sayfa/Page | 39

IGU J. Soc. Sci., 4 (2), Spec. Iss. of ICEFM 2017, pp. 33-46. 


\section{Uygulama Sonuçları}

E7 ülkelerinde PPP'nin geçerliğinin araştırıldığı bu çalışmada Ocak 2000 - Ekim 2016 aylık verileri kullanılıştır. Analizde kullanılan nominal döviz kuru ve tüketici fiyat endeksi verileri IMF- IFS (International Financial Statistics) veri tabanından temin edilmiştir. $y_{i, t}$ logaritmik reel döviz kurunu, $s_{i, t}$ logaritmik nominal döviz kurunu, ${ }^{p_{u s, t}}$ logaritmik fiyat indeksini (US), ve $p_{i, t}$ ise i. ülkenin logaritmik fiyat indeksini göstermek üzere reel döviz kuru serisi aşağıdaki eşitlikten elde edilmiştir.

$$
y_{i, t}=s_{i, t}+p_{u s, t}-p_{i, t}
$$

E7 ülkelerinde PPP geçerliğini birim kök testleri yardımıyla incelemeden önce reel döviz kuru serilerinin doğrusal olup olmadıkları Harvey ve Leybourne (2007) ve Harvey vd. (2008) testleri ile Tablo 2'de incelenmiștir.

Tablo 2: Doğrusallık Test Sonuçları

\begin{tabular}{|c|c|c|c|c|}
\hline \multirow{2}{*}{ Ülke } & \multirow{2}{*}{ Harvey vd. (2008) } & \multicolumn{3}{|c|}{ Harvey ve Leybourne (2007) } \\
\hline & & $\% 10$ & $\% 5$ & $\% 1$ \\
\hline Brezilya & 4.27 & $11.8^{* * *}$ & $11.92^{* *}$ & 12.16 \\
\hline Çin & $6.6^{* *}$ & $12.46^{* * *}$ & $12.53^{* *}$ & 12.67 \\
\hline Endonezya & $23.74^{*}$ & $26.02^{* * *}$ & $26.19^{* *}$ & $26.49^{*}$ \\
\hline Hindistan & 1.86 & 5.17 & 5.22 & 5.32 \\
\hline Meksika & 3.63 & 2.86 & 2.98 & 3.22 \\
\hline Rusya & $16.68^{*}$ & $20.37^{* * *}$ & $20.5^{* *}$ & $20.73^{*}$ \\
\hline Türkiye & 1.66 & $9.51^{* * *}$ & $9.59^{* *}$ & 9.72 \\
\hline
\end{tabular}

Not: Harvey vd. (2008) testi kritik değerleri \%1, \%5 ve \%10 için sırasıyla 9.21, 5.99 ve 4.60 şeklindedir. Harvey ve Leybourne (2007) testi kritik değerleri \%1, \%5 ve \%10 için sirasiyla 13.27, 9.48 ve 7.77 şeklindedir. *** ve *** sirasiyla \%1, \%5 ve \%10 için doğrusallı temel hipotezinin reddedildiğini ifade etmektedir. 
E7 ülkeleri reel döviz kuru serileri için yapılan Harvey vd. (2008) doğrusallık testi sonucuna göre Çin, Endonezya ve Rusya serileri doğrusal olmayan yapıdadır. Harvey ve Leybourne (2007) doğrusallık testine göre ise Brezilya, Çin, Endonezya, Rusya ve Türkiye'ye ait serilerin doğrusal olmayan yapıda olduğu sonucuna ulaşılmıştır.

Brezilya ve Türkiye için doğrusallık testleri farklı sonuçlar verdiğinden bu ülkeler için hem doğrusal birim kök testi hem de doğrusal olmayan birim kök testi yapılmıştır. Analizlerde maksimum gecikme uzunluğu Schwert (1989) tarafından önerilen yöntem ile belirlemiştir. E7 ülkeleri için PPP geçerliğinin araştırıldığı birim kök test sonuçları Tablo 3 ve Tablo 4'de yer almaktadır.

Tablo 3: Doğrusal Birim Kök Test Sonuçları

\begin{tabular}{|c|c|c|c|c|c|c|c|c|}
\hline \multirow{2}{*}{ Ülke } & \multicolumn{4}{|c|}{ Model AA } & \multicolumn{4}{|c|}{ Model CC } \\
\hline & $\mathrm{k}$ & İstatistik d. & TB1 & TB2 & $\mathrm{k}$ & İstatistik d. & TB1 & TB2 \\
\hline Brezilya & 6 & -1.7720 & 2003M7 & 2011M9 & 5 & $-5.4627^{* * *}$ & 2004M6 & 2012M1 \\
\hline Hindistan & 9 & -2.6715 & $2007 \mathrm{M} 3$ & 2009M6 & 9 & $-5.9380^{* *}$ & 2003M9 & 2010M7 \\
\hline Meksika & 8 & -3.3100 & 2009M3 & 2014M11 & 8 & -4.5769 & $2002 \mathrm{M} 11$ & 2013M8 \\
\hline Türkiye & 2 & -1.7882 & 2003M4 & 2006M7 & 6 & -5.2752 & 2003M2 & 2008M11 \\
\hline
\end{tabular}

Not: TB1 ve TB2 birinci ve ikinci kırılma tarihlerini göstermektedir. Test istatistikleri Lee ve Strazicich (2003) çalışmasında yer alan kritik değerler ile kıyaslanmıştır. ${ }^{* * *}$ ve ${ }^{* * *}$ sırasıyla $\% 1, \% 5$ ve $\% 10$ için birim kök temel hipotezinin reddedildiğini ifade etmektedir.

Doğrusal özellik sergileyen ülkeler için PPP'nin geçerliliği Lee ve Strazicich (2003) iki kırılmaya izin veren birim kök testi ile incelenmiştir. Sabitte iki kırılmaya izin veren model için tüm ülkelerde PPP geçerli değildir. Sabitte ve trendde iki kırılmaya izin veren model için Brezilya ve Hindistan'da PPP'nin geçerli olduğu, diğer iki ülkede geçerli olmadığı sonucuna ulaşılmıştır.

Sayfa/Page | 41

IGU J. Soc. Sci., 4 (2), Spec. Iss. of ICEFM 2017, pp. 33-46. 
Tablo 4: Doğrusal Olmayan Birim Kök Test Sonuçları

Sos. Bil. Derg.,

4 (2), ICEFM 2017,

Özel Sayısı,

ss. 33-46.

\begin{tabular}{|c|c|c|c|c|c|c|}
\hline \multirow{2}{*}{ Ülke } & \multicolumn{3}{|c|}{ Sollis $\mathrm{c}$} & \multicolumn{3}{|c|}{ Sollist } \\
\hline & $\mathrm{k}$ & $H o: \phi_{1}=\phi_{2}=0$ & $H o: \phi_{2}=0$ & $\mathrm{k}$ & $H o: \phi_{1}=\phi_{2}=0$ & $H o: \phi_{2}=0$ \\
\hline Brezilya & 1 & 3.0933 & 0.0781 & 1 & 4.3545 & 0.0066 \\
\hline Çin & 0 & $4.7307^{* * *}$ & 1.9570 & 0 & 4.0468 & 1.1854 \\
\hline Hindistan & 9 & 2.4354 & 0.0523 & 9 & 2.8719 & 0.1066 \\
\hline Rusya & 2 & 4.0596 & 3.5595 & 2 & 2.1782 & 0.3845 \\
\hline Türkiye & 2 & 2.5216 & 0.2208 & 2 & 2.8151 & 0.0087 \\
\hline
\end{tabular}

Not: Tabloda c indisi ortalamadan arındırılmış, $\mathrm{t}$ indisi trendden arındırılmış yapıyı göstermektedir. Test istatistikleri Sollis (2009) çalışmasında yer alan kritik değerler ile kıyaslanmıştır. ${ }^{* * *}$ ve ${ }^{* * *}$ sırasıyla $\% 1, \% 5$ ve $\% 10$ için birim kök temel hipotezinin reddedildiğini ifade etmektedir.

Tablo 4'de Brezilya, Çin, Hindistan, Rusya ve Türkiye için Sollis (2009) doğrusal olmayan birim kök test sonuçları yer almaktadır. Ortalamadan arındırılmış yapı için sadece Çin'de PPP’nin geçerli olduğu görülmektedir. Trendden arındırılmış yapı için ise tüm ülkelerde PPP'nin geçerli olmadığı sonucuna varılmıştır.

\section{Sonuç}

İsveçli iktisatçı Gustav Cassel (1918) çalışması ile literatüre kazandırılan Satınalma Gücü Paritesi uluslararası ekonominin ilgi çeken konuları arasındadır. Ülkeler arasındaki fiyat düzeyi farklılıklarını ortadan kaldırarak, farklı para birimlerinin satınalma gücünü eşitleyen değişim oranı Satınalma Gücü Paritesi olarak tanımlanmaktadır. Ülke ve/veya ülke grupları için Satınalma Gücü Paritesinin geçerliliğinin araştırılmasında yaygın olarak kullanılan reel döviz kurunun durağanlığının araștırılmasıdır.

Çalışmada gelişen 7 ülke için Satınalma Gücü Paritesi geçerliliği araştırılmıştır. Reel döviz kuru serilerinin doğrusal olup olmadı̆̆ Harvey ve Leybourne (2007) ve Harvey vd. (2008) doğrusallık testleri ile incelenmiștir. Analize göre, doğrusal seriler için Satınalma Gücü Paritesi geçerliliği Lee ve Strazicich (2003) iki yapısal kırılmaya izin veren birim kök testi ile araştırılmış ve sadece Brezilya ve Hindistan'da sabitte ve trendde kırılmaya izin veren modelde geçerli olduğu sonucuna ulaşılmıştır. Doğrusal olmayan seriler için Satınalma Gücü Paritesi geçerliliği Sollis (2009) doğrusal olmayan birim kök testi ile araştırılmış ve sadece Çin'de ortalamadan arındırılmış 
modelde geçerli olduğu sonucuna ulaşılmıştır. Elde edilen bulgular birçok durumda E7 ülkelerinde Satınalma Gücü Paritesinin geçerliliğinin kabul edilmediğini göstermektedir.

\section{KAYNAKÇA}

AKHTAR, Kalsoom, Mubeen MUJAHID, Muhammad A. ZUBERI, and Muhammad SHAZIB, "Purchasing Power Parity:Implacation with Respect to Pakistan and USA" Research Journal of Finance and Accounting, Vol. 5(4), 2014, s.193-201.

BAHMANI-OSKOOEE, Mohsen, Tsangyao CHANG, and Kuei-Chiu LEE, "Purchasing Power Parity in the BRICS and the MIST Countries: Sequential Panel Selection Method". Review of Economics \& Finance, Vol.4, 2014, s.112.

BAHMANI-OSKOOEE, Mohsen, Tsangyao CHANG, Tsung-Hsien CHEN and Han-Wen TZENG, "Revisiting Purchasing Power Parity in Eastern European Countries: Quantile Unit Root Tests”, Empirical Economics, Vol.52(2), 2017, s.463-483.

BOZOKLU, Şeref ve Veli YILANCI, “Reel Döviz Kurlarının Durağanlığı: E7 Ülkeleri İçin Ampirik Bir İncele” Maliye Dergisi, Vol.158, 2010, s.587-606.

CERRATO, Mario and Nicholas SARANTİS, "Does Purchasing Power Parity Hold in Emerging Markets? Evidence from a Panel of Black Market Exchange Rates", International Journal of Finance and Economics, Vol. 12, 2007, s.427-444.

CHANG, Hsu-Ling, Chi-Wei SU, Meng-Nan ZHU and Pei LIU, "Long-run Purchasing Power Parity and Asymetric Adjustment in BRICs", Applied Economics Letters, Vol.17, 2010, s.1083-1087.

CHANG, Tsangyao, Chia-Hao LEE and Ken HUNG, "Can the PPP Stand on the BRICS? The ADL Test for Threshold Cointegration" Applied Economics Letters, Vol.19, 2012, s.1123-1127.

CUESTAS, Juan Carlos and Paulo J. REGIS, "Purchasing Power Parity in OECD Countries: Nonlinear Unit Root Tests Revisited" Economic Modelling, Vol.32, 2013, s. 343-346.

ÇAĞLAYAN, Ebru ve Nazan ŞAK, "OECD Ülkelerinde Satınalma Gücü Paritesi: Panel Eşbütünleşme Yaklaşımı”, Marmara Üniversitesi İ.İ.B.F. Dergisi, C:26 (1), 483-500. 
Sayfa/Page | 44

İGÜ Sos. Bil. Derg., 4 (2), ICEFM 2017, Özel Sayıs ss. 33-46
ÇEVIŞ̧, İsmail ve Reşat CEYLAN, "Kırılgan Beşlide Satın Alma Gücü Paritesi (SAGP) Hipotezinin Test Edilmesi”, Journal of Yasar University, Vol.10(37), 2015, s.6381-6477.

GÜRIŞ, Burak and Muhammed TIRAŞOĞLU, "The Validity of Purchasing Power Parity in the BRICS Countries", Prague Economic Papers, 2017, DOI: https://doi.org/10.18267/j.pep.654, [Online] https://www.vse.cz/ pep/654.

GÜRIŞ, Burak, Yaşar Serhat YAŞGÜL and Muhammed TIRAŞOĞLU, "An Empirical Investigation of Purchasing Power Parity (PPP) for NORDIC Countries: Evidence from Linear and Nonlinear Unit Root Tests", International Journal of Economic Perspectives, Vol. 10(1), 2016, s. 133.

HARVEY, David I., and Stephen J. LEYBOURNE, “Testing for Time Series Linearity", Econometrics Journal, Vol.10, 2007, s. 149-165.

HARVEY, David I., Stephen J. LEYBOURNE and Bin XIAO, "A Powerful Test for Linearity When the Order of Integration is Unknown", Studies in Nonlinear Dynamics \& Econometrics, Vol.12 (3), 2008, (article 2).

HOOI, Lean Hooi and Russell SMYTH, "Are Asian Real Exchange Rates Mean Reverting? Evidence from Univariate and Panel LM Unit Root Tests with One and Two Structural Breaks", Applied Economics, Vol:39, 2007, s.21092120 .

KAPETANIOS, George, Yongcheol SHIN, and Andy SNELL, "Testing for a Unit Root in the Nonlinear STAR Framework", Journal of Econometrics, Vol.112, 2003, s. 359-379.

LEE, Junsoo and Mark C. STRAZICICH, "Minimum Lagrange Multiplier Unit Root Test with Structural Breaks" The Review of Economics and Statistics, Vol.85(4), 2003, s.1082-1089.

NUSAIR, Salah A. "Testing the Validty of Puchasing Power Parity for Asian countries During the Current Float", Journal of Economic Development, Vol.28 (2), 2003, s.129-147.

PENG, Hongfeng, Zhijie LIU, and Tsangyao CHANG, "Revisiting Purchasing Power Parity in BRICS Countries Using more Powerful Quantile Unit Root Tests with Stationary Covariates" Communications in StatisticsTheory and Methods, 2016. s. 1-7.

SCHWERT, G. William, "Tests for Unit Roots: A Monte Carlo Investigation", Journal of Business and Economic Statistics, Vol.7, 1989, s.147-160.

SOLLIS, Robert, "A Simple Unit Root Test against Asymmetrical STAR Nonlinearity with an Application to Real Exchange Rates in Nordic Countries", Economic Modelling, Vol. 26(1), 2009, s. 118-125. 
ŞENER, Sefer, Veli YILANCI ve Esra CANPOLAT, "Satın Alma Gücü Paritesi ve Varyasyonlarının Türkiye için Sınanması", Uluslararası Yönetim İktisat ve İşletme Dergisi, Vol.11(5), 2015, s.53-63.

TIRAŞOĞLU, Burcu Yıldırım, "Yapısal Kırılmalı Birim Kök Testleri ile OECD Ülkelerinde Satın Alma Gücü Paritesi Geçerliliğinin Testi”, Ekonometri ve İstatistik Dergisi, Sayı.20, s.68-87.

TÜİK, "Satınalma Gücü Paritesi”, TÜİK Yayınları, Yayın No:3145, Ankara, 2008.

Sayfa/Page | 45

IGU J. Soc. Sci., 4 (2), Spec. Iss. of ICEFM 2017, pp. 33-46.

\section{Summary}

As one of the important and controversial topics in international economy, the Purchasing Power Parity (PPP) draws the attention of many researchers today. Introduced to literature first by the Swedish economist Gustav Cassel (1918), the PPP became a popular field of study with the collapse of the Bretton Woods system in 1973. The PPP is, by definition, a conversion ratio that evens up the purchasing power of different currencies by eliminating the price level differences between countries.

Although there are different methods in literature used to study the validity of the Purchasing Power Parity, the popular method is to study the stationarity of the real foreign exchange rate. One can observe that there is not one common result obtained with respect to the validity of PPP. Some of the reasons include the country/country group studied, the period analyzed and the differences between the econometric methods applied.

The purpose of this study is to analyze the validity of the Purchasing Power Parity of seven emerging countries (E7) by using relevant econometric methods. Prior to studying the validity of the Purchasing Power Parity in E7 countries via unit root tests, the linearity of real foreign exchange rate data was examined. The Harvey and Leybourne (2007) and Harvey vd. (2008) linearity tests that offer the major advantage of not being influenced by linearity levels were used as linearity tests. The unit root test the PPP validity of which was introduced to literature by Sollis (2009) was used for the series that were nonlinear. The unit root test the PPP validity of which was introduced to literature by Lee and Strazicich (2003) was used for the series that were linear.

The validity of the Purchasing Power Parity for E7 is examined based on the monthly data for the period January 2000 - October 2016. When the real foreign exchange rate series for the E7 countries are studied, nonlinearity is observed for China, Indonesia and Russia according to Harvey vs. (2008) 
Sayfa/Page | 46

İGÜ Sos. Bil. Derg.,

4 (2), ICEFM 2017, Özel Sayısı, ss. 33-46. linearity test results and for Brazil, China, Indonesia, Russia and Turkey according to the Harvey and Leybourne (2007) linearity test results. The Lee and Strazicich (2003) linear unit root test with two breaks is used for Brazil, India, Mexico and Turkey and it is found that the PPP does not apply for these countries. According to the nonlinear Sollis (2009) unit root test result for Brazil, China, India, Russia and Turkey, the PPP applies only for China for the structure independent from average whereas the PPP does not apply for these countries for the structure independent from the trend. The findings indicate that the validity of the Purchasing Power Parity is not accepted in many cases for E7 countries. 